\title{
ASSESSING THE EFFECTIVENESS OF AN ONLINE TEACHING INTERVENTION IN REDUCING THE PUBLIC SPEAKING APPREHENSION (PSA) AMONG THE SECOND-YEAR LAW UNDERGRADUATES IN KOTELAWALA DEFENCE UNIVERSITY
}

\author{
WS Sudusinghe ${ }^{1}$ and CKW Gamage ${ }^{2}$ \\ Department of Languages, KDU, Sri-Lanka, sudusinghews@ @du.ac.lk ${ }^{1}$ \\ Department of Nursing \& Midwifery, Faculty of Allied Health Sciences, KDU, Sri-Lanka ${ }^{2}$
}

\begin{abstract}
Public speaking skills are a mandatory requirement for law undergraduates to become competent future lawyers. Public Speaking Anxiety (PSA) is one of the crucial issues faced by law students. Therefore, the current study was designed as a pretest-posttest design to evaluate the effectiveness of an online teaching intervention in reducing the PSA among second-year law undergraduates at the General Sir John Kotelawala Defence University (KDU), SriLanka. More than fifty-three individuals from two of the four groups prepared to undergo lectures were randomly chosen for the study. The online teaching intervention continued for 15 weeks via the zoom platform. It consisted of gradual exposure, Communication Orientation Modification (COM), skills training, humour, and simple breathing exercises. A self-administered questionnaire consisted of an assessment of socio-demographic data followed by the Personal Report of Public Speaking Anxiety (PRPSA) scale was used in the data collection. The data were analysed using descriptive and inferential analysis in Statistical Package for the Social Sciences (SPSS) 23.0. According to the normality tests, the distribution of the pre-test data was normal, but the post-test data was not normal. Hence, the researcher used both parametric and non-parametric tests. The mean ( $\pm S D)$ age of the participants was 22.15 ( \pm 4.857$)$ years, and the majority of them were females (83.0\%: $n=44)$. A Wilcoxon signed-rank test showed that the 15-week online teaching intervention on managing the PSA had resulted in a statistically significant reduction in the PRPSA score $(Z=-5.761, p=0.000)$. Hence, the current study has revealed that the online teaching intervention conducted among the second-year Law undergraduates in managing the PSA has successfully reduced the PSA among the study participants. However, further experimental research is needed to assess associated factors related to PSA among Law undergraduates.
\end{abstract}

KEYWORDS: Law undergraduates, Online teaching intervention, Public Speaking Apprehension (PSA), Personal Report of Public Speaking Anxiety (PRPSA) scale

Corresponding Author: W S Sudusinghe, Email: sudusinghews@kdu.ac.lk 


\section{INTRODUCTION}

According to the World Health Organisation, "Mental Health" is defined as a state of well-being in which individuals with the capacity to understand their abilities, manage coping strategies when dealing with stressful conditions in everyday life can work efficiently and successfully, and contribute to his or her community (Otorkpa, 2019). Mental health has been frequently conceptualised as an entirely positive effect, remarked by feelings of happiness and a sense of awareness over the environment (Lamers et al., 2011). Therefore, mental health is an essential aspect of health, and the WHO asserts that "there is no health without mental health" (Otorkpa, 2019). The identified mental disorders are depression, anxiety, stress, schizophrenia, and substance-related disorders that involve a vast range of problems with numerous symptoms. Further, they generally specify some combination of conflicting emotions, behaviours, thoughts, and relationships with others (Galderisi et al., 2015). As mentioned in the recent reports of the $\mathrm{WHO}$, about 450 million people globally suffer from mental disorders (Otorkpa, 2019).

According to Jurewicz (2015), young adulthood is one of the most vulnerable categories, where young people encounter many problems related to mental health. The mental health issues faced by young adults by the time they enter their university life can bring potential threats to the success of their academic life (McLafferty et al., 2017). Hence, university undergraduates are one of the particular risk groups due to volatile lifestyle deviations connected with new friendships and social norms (Sravani et al., 2018). Moreover, their perception and coping strategies are affected during the transition from secondary education to university education. In this transition period, they must adjust to new routines and active learning methods (Orgilés et al., 2021).

Public Speaking Anxiety (PSA), which is also known as Public Speaking Apprehension, is classified as one of the social anxiety disorders as per the Diagnostic and Statistical Manual of Mental Disorders $5^{\text {th }}$ version (DSM -5) (APA, 2013). The PSA is also labelled as Glossophobia and classified as a state of being nervous or distress generated with the anticipation of something intimidating. Moreover, the PSA has been identified as a predominant social phobia amongst young adults today (Herath, 2019). Further, it has a prevalence in $15 \%$ to $30 \%$ of the general population (Pull, 2012). Despite being experts in terms of their knowledge, poor public speaking skills become a threat to the success of many professionals. Moreover, in general, society has a negative impression of the people with PSA due to their inability to generate a positive impression.

There are three major divisions of the symptoms resulting from PSA: physical, verbal, and non-verbal. A person suffering from PSA will experience physical symptoms such as neck rigidity, acute hearing, increased oxygen intake, raised heartbeat, spasm of upper back muscles, enhanced sweating, and dilated pupils. Further, they may undergo verbal and no-verbal symptoms such as tense and shaking voice, vocalised pauses, and disturbing body language, respectively (Furmark, 2002). The research studies have revealed that females tend to have higher levels of a social phobia than males (McLean et al., 2011). Moreover, apprehension in communication can result in a weak competency and reluctance in engaging with public speaking; primarily, three mechanisms utilised to treat the apprehension, such as enhancing the levels of competency and skill-building, systematic desensitisation, and cognitive restructuring (Colbeck, 2011). It identifies that the approaches mentioned above can reinforce the students' performance (Colbeck, 2011).

Systematic desensitisation indicates that when people get frequent exposure to what brings them fear, it gradually reduces their anxiety (Bodie, 2010). It identified that one of the common origins of anxiety among people in public speaking is the feeling of newness and uncertainty. Hence gaining more experience in public speaking can potentially reduce the sense of newness and uncertainty. Systematic desensitisation, which is associated with encouraging the person to get repetitively engaged in the activity or the exercise, will bring high anxiety levels. People may begin to feel a sense of comfort as a consequence, and this may reduce the feeling of newness. In addition, it will facilitate them to experience a feeling of relaxation and easiness (Colbeck, 2011). It provides a gradual and systematic exposure for the individuals to the stimuli which cause the stressful condition. 
Cognitive restructuring involves a change in the perspective about how the individuals view things. The initial step of coping with the PSA is to cognitively process fears and anxieties to comprehend that most of the thoughts generated within the PSA are unreasonable (Allen et al., 1989). Cognitive restructuring is classified as one of the effective mechanisms in reducing the levels of apprehension in communication. It focuses on directing the individuals with high levels of PSA to the observation and guidance of an instructor. The role of the instructor is to carefully understand the weaknesses within the individuals and assist them in generating optimism and motivation (Arnold, 2018). Improving the skills of the undergraduates through the training programmes is one of the critical interventions employed at the university levels in improving public speaking skills. The guidance that they receive from the instructors can boost their level of confidence. This method is identified as a very effective mechanism in reducing the PSA through the results of an experimental study (Colbeck, 2011).

Communication-orientation modification therapy (COM therapy) is one of the efficient types of cognitive restructuring that enables people to consider the act of public speaking as a conversation rather than a public speaking performance (Motley, 1997). It is commonly identified as a very effective strategy in managing the PSA.

The skills training programmes have measurable success in reducing PSA (Allen et al., 1989). A previous study was conducted to test the effectiveness of a skills-based programme to reduce anxiety during public speaking (Pribyl et al., 2001). Twenty-five Japanese college sophomores got exposed to a systematic approach for developing a presentation that was theoretically linked to mechanisms to reduce communication apprehension. Students have been asked to conduct four presentations which both teacher and their peers graded. Results indicated that the experimental group reported a significant drop in public speaking anxiety than the control group (Pribyl et al., 2001). Further, it was noted that the relaxation therapies like simple breathing exercises (Ebrahimi et al., 2019) had been used extensively in managing the PSA. Moreover, humour usage has been identified as a viable strategy to relieve anxiety (Menéndez-Aller et al., 2020).

The PSA is classified as one of the prevalent issues by law undergraduates. One of the essential skills of a lawyer is good public speaking skills, and lawyers are supposed to maintain effective interactions with their clients. Further, they should be capable of delivering arguments convincingly and fruitfully before the court. Hence, improving the public speaking skills of law undergraduates is one of the most valuable investments for their future. This has to be done at the initial stages of their university education so that by the time they become graduates, they will be able to enter the world of professionalism with high confidence levels. When the undergraduates are given the rightful exposure to improve their public speaking skills, many positive changes will happen in their personalities. Hence, it is evident that eradicating the PSA among law undergraduates is of greater significance as it can potentially impend their confidence as future lawyers (Brown, 2015).

Though PSA is an emerging issue throughout the world, the number of studies conducted in the Sri Lankan context related to PSA is very low, especially related to law undergraduates. Further, no studies were found to assess the effectiveness of an online teaching intervention in reducing the PSA among the law undergraduates in the Sri Lankan setting. The university education in Sri Lanka has largely shifted to online education with the outbreak of the COVID-19 pandemic. Therefore, it has become a mandatory requirement in research to assess the effectiveness of online education. It is vital to investigate how far online education successfully achieves similar outcomes obtained via onsite education. Hence, this study aimed to assess the effectiveness of an online teaching intervention in reducing the PSA among the secondyear law undergraduates who follow compulsory public speaking modules at the General Sir John Kotelawala Defence University, Sri Lanka. 


\section{METHODOLOGY}

\section{Study design, study population and sample size}

The study was conducted as a quasi-experimental pretest post-test design among second-year Law undergraduates who study a compulsory 'Public Speaking' module at the General Sir John Kotelawala Defence University, Sri-Lanka. Usually, the lectures of second-year Law undergraduates are delivered by dividing the students into four equal groups. The study sample of 53 individuals was selected by choosing two groups randomly out of those four groups. The online teaching intervention was carried out for 15 weeks via the zoom platform, and PSA was measured before and after the online teaching intervention.

\section{Data collection}

A self-administered questionnaire consisted of an assessment of socio-demographic data followed by the Personal Report of Public Speaking Anxiety (PRPSA) scale - version 1.0 was used for pre- and post-test data collection. At the end of the intervention, the post-test was done to assess the PSA levels of the students. PRPSA scale is a 34-item one developed by McCroskey, J. C. (McCroskey, 1970), an excellent measure of PSA. The original creators of the scale granted permission for the scale to be used. Cronbach's alpha of the PRPSA scale ranges from 0.84 to 0.94 (Mörtberg et al., 2018), proving that the scale is very reliable. Furthermore, the severity of the PSA is categorised in PRPSA under three levels (High $=>131$, Low $=<98$ and Moderate $=98-131)$ and the response to each item was scaled in a Likert scale (1- Strongly Disagree, 2-Disagree, 3- Neutral, 4-Agree, 5-Strongly Agree) (McCroskey, 1970). The questionnaire was piloted among ten second-year law undergraduates to evaluate cultural appropriateness and comprehension, and they were excluded from the study population.

\section{Online teaching intervention}

The principal investigator, an academic member who teaches compulsory 'Public Speaking' module for the students, carried out the online teaching intervention via the zoom platform. The intervention group was exposed to an online teaching intervention of consecutive 15 weeks. During this period, the students were given both theoretical and practical exposure in managing the PSA. Throughout the fifteen weeks, the students were given comprehensive knowledge based on the theoretical framework of PSA management through the compulsory module. The students were asked to keep their cameras on during all the sessions, exposing them to an audience watching them. The breakout room option was used for group activities. The online teaching intervention in the current study was developed based on the previous research studies conducted on PSA worldwide (Anderson et al., 2005; Ayres et al., 2000; Dwyer and Davidson, 2007; Neer and Kirchner, 1991; Pribyl et al., 2001; Xu, 2015). The views of the subject and mental health experts were obtained when forming the online teaching intervention.

During the first two weeks, the students were exposed to the techniques in gradual exposure therapy. Through the use of various systematic techniques, the students were gradually exposed to public speaking that would cause them distress. The goal of gradual exposure therapy was to create a safe, comfortable environment to reduce anxiety. Element of humour was also used to expose the students to the act of public speaking. The students were divided into small groups (4-5 members) via the breakout room option, and each group was asked to prepare a speech on a topic that contains the element of humour: ethical, moral, and legal, which does not specify any individual or organisation. In the end, a randomly selected presenter from each group delivered the speech on the given topic for two to three minutes within their small group, and the principal investigator was there as an observer. This technique was used to make the students comfortable at the thought of delivering a speech. In addition to the practical tasks, they were also taught the theoretical framework for managing their PSA.

Moreover, the techniques in the Communication Orientation Modification (COM) therapy were utilised in the teaching. COM therapy is one of the efficient types of cognitive restructuring that enables people to consider public speaking as a conversation rather than a performance. The students were taught to practice the habit of looking at public speaking as a conversation that leads to an increasing level of confidence. When 
public speaking is imagined as a normal conversation, the students tend to reduce their apprehension as they feel that they have already gathered experiences and skills that they can utilise. Further, they have been asked to visualise their act of delivering the speech before they deliver it to lessen their fear. Moreover, cognitive restructuring was used in teaching to give the students the ability to view public speaking as less threatening. Cognitive restructuring is taught as a selfmanagement skill for dealing with negative feelings through the articulation of specific thoughts that underlie the distressing feeling and the objective evaluation of evidence supporting those thoughts (Mueser et al., 2015). Furthermore, the students were taught the importance of simple breathing exercises to relieve anxiety before presentations.

During three to five weeks, the students were asked to deliver speeches on simple topics of their interest. They were given a period of four to five minutes per speech. Then, each student received feedback from the group and the principal investigator. During this stage, the students were asked to perform simple breathing exercises before they delivered the speech to reduce apprehension. At the end of each session, the students were assisted with positive feelings to realise their irrationality of PSA by discussing it.

From the sixth to the ninth week, the students were instructed to deliver speeches on a more specific topic, and the number of students in a group was also increased gradually by decreasing the number of groups. As they were from the Law stream, the students were asked to prepare for speeches on Law related topics. Further, the students were subjected to a series of lectures that guide them in selecting a topic, understanding the psychology and the audience's needs, and how to carry out a proper research on a topic they have selected. In addition, the students were taught how to write their script correctly, add citations in a speech, and select reliable sources for information. Afterwards, the students were asked to prepare a proper script of their speech and feedbacks were given, including suggestions for further improvements. The time duration given for their speeches was also gradually increased up to ten minutes.
During the period of $10-12$ weeks, the students were exposed to the delivery of speeches on advanced topics ranging from fifteen to twenty minutes. Furthermore, they were given the chance of delivering their speeches in front of all the students. Further, the students were also asked to share the recorded versions of their presentations and feedbacks were given individually before the presentation. As a result, during the last two weeks of the interventions, the students could deliver lengthy speeches on advanced topics coupled with techniques of professionalism. Moreover, they were trained to become competent in giving constructive feedback on the speeches delivered by their colleagues.

\section{Data analysis}

Descriptive and inferential data analysis were performed with Statistical Package for the Social Sciences (SPSS) 23.0 version. Frequencies and the percentages of the socio-demographic data were analysed in the descriptive data analysis. The normality of the data distribution was evaluated using the Shapiro Wilk test, histograms and Q-Q plot analysis. According to the normality test, the distribution of the pre-test data was normal, and that of the post-test data was not normal.

Hence, both parametric and non-parametric tests were used. T-tests and ANOVAs were employed to evaluate the significant differences in the pre-test data across different socio-demographic variations with the PRPSA score. Meanwhile, the Mann-Whitney U and Kruskal Wallis tests were performed in the post-test among various socio-demographic variations with the PRPSA score. A significance of $<0.05(\mathrm{p}=<0.05)$ was considered as statistically significant. Wilcoxon signed-rank test was used to evaluate whether there was any statistically significant difference between the PRPSA scores in the pre and post-tests. 


\section{RESULTS}

\section{Socio-Demographic data}

Table 1 -Socio demographic data

\begin{tabular}{|c|c|c|c|}
\hline Demographic & $\begin{array}{l}\text { Characte- } \\
\text { ristics }\end{array}$ & No. & $\%$ \\
\hline \multirow{2}{*}{ Gender } & Male & 9 & 17.0 \\
\hline & Female & 44 & 83.0 \\
\hline \multirow{4}{*}{$\begin{array}{l}\text { The highest } \\
\text { grade obtained } \\
\text { for G.C.E A/L } \\
\text { General } \\
\text { English? }\end{array}$} & $\overline{\mathrm{A}}$ & 26 & 49.1 \\
\hline & B & 11 & 20.8 \\
\hline & $\mathrm{C}$ & 14 & 26.4 \\
\hline & $S$ & 2 & 3.8 \\
\hline \multirow{2}{*}{$\begin{array}{l}\text { Taken part in } \\
\text { extra-curricular } \\
\text { activities }\end{array}$} & No & 16 & 30.2 \\
\hline & Yes & 37 & 69.8 \\
\hline \multirow[t]{2}{*}{ Drama } & No & 26 & 49.1 \\
\hline & Yes & 27 & 50.9 \\
\hline \multirow[t]{2}{*}{ Toastmaster } & No & 37 & 69.8 \\
\hline & Yes & 16 & 30.2 \\
\hline \multirow[t]{2}{*}{ Singing } & No & 51 & 96.2 \\
\hline & Yes & 2 & 3.8 \\
\hline \multirow[t]{2}{*}{ Announcing } & No & 48 & 90.6 \\
\hline & Yes & 5 & 9.4 \\
\hline \multirow[t]{2}{*}{ MUN } & No & 51 & 96.2 \\
\hline & Yes & 2 & 3.8 \\
\hline \multirow[t]{2}{*}{ Debating } & No & 37 & 69.8 \\
\hline & Yes & 16 & 30.2 \\
\hline \multirow{2}{*}{$\begin{array}{l}\text { Presented an } \\
\text { item before }\end{array}$} & No & 7 & 13.2 \\
\hline & Yes & 46 & 86.8 \\
\hline \multirow{2}{*}{$\begin{array}{l}\text { Followed any } \\
\text { courses related } \\
\text { to public } \\
\text { speaking }\end{array}$} & No & 43 & 81.1 \\
\hline & Yes & 10 & 18.9 \\
\hline
\end{tabular}

The mean $( \pm \mathrm{SD})$ age of the participants was 22.15 $( \pm 4.857)$ years. The majority of them were females (83.0\%: $\mathrm{n}=44)$. Most of the study participants $(86.8 \%$ : $\mathrm{n}=46$ ) had the experience of presenting an item in front of an audience. Furthermore, it was revealed that the participants have engaged in extra-curricular activities concerning public speaking such as Toastmaster (30.2 $\% \mathrm{n}=16$ ), Debating (30.2\%: $\mathrm{n}=16)$ and Model United Nations (MUN) (3.8\%: n=02). Further, most of the participants $(86.8 \%$ : $n=46)$ have presented an item in front of an audience. However, most of the participants (81.1\%: $n=43$ ) have not followed any courses related to public speaking (Table 1).

\section{Pre-assessment of PSA}

The mean score of the PRPSA obtained by the pre-test was $102.70( \pm 18.321)$. There was a significant mean difference in the PRPSA scores between the two genders $(p=0.042)$, engagement in the extra-curricular activities like debating $(\mathrm{p}=0.001)$, MUN ( $\mathrm{p}=0.004)$, following the courses related to public speaking $(\mathrm{p}=0.020)$ and previous exposure to presenting an item in front of an audience ( $\mathrm{p}=0.036)$. This study found that the PRPSA score of the male participants had a statistically significantly lower score $(91.44 \pm 22.604)$ compared to that of the female participants $(105.00 \pm$ 15.186), $\mathrm{t}(51)=-2.087, \mathrm{p}=0.042$. In addition, the PRPSA score of the study participants who are engaged in MUN had a statistically significantly lower score $(67.00 \pm 18.385)$ compared to that of the participants who were not engaged $(104.10 \pm 17.011) \mathrm{t}(51)=0.542$, $\mathrm{p}=0.004$. Further, it was revealed that the PRPSA score of the study participants who have done debating had a statistically significantly lower score $(90.63 \pm 18.998)$ compared to that of the participants who have not done debating $(107.92 \pm 15.546), \mathrm{t}(51)=3.474, \mathrm{p}=0.001$. Furthermore, there was a statistically significantly lower PRPSA score among those who have presented an item in front of an audience $(100.65 \pm 17.503)$ compared to that of those who have not (116.14 \pm 19.196), $\mathrm{t}(51)=2.156, \mathrm{p}=0.036$ and also, among those who have followed courses related to public speaking $(90.70 \pm 20.451)$ compared to those who have not $(105.49 \pm 16.844), \mathrm{t}(51)=2.402, \mathrm{p}=0.020$.

\section{Posttest assessment of PSA}

A Wilcoxon signed-rank test showed that the 15 week online teaching intervention on managing the public speaking apprehension had resulted in a statistically significant change in reducing the public speaking apprehension $(\mathrm{z}=-5.761, \mathrm{p}=0.000)$. The median PRPSA score was reduced from 101.00 to 74.00 after the 15 weeks of online teaching intervention, and the mean score of the PRPSA obtained in the post-test was $82.50( \pm 18.672)$. Further, it was noted that there was no statistically significant difference between the two genders $(\mathrm{p}=0.138)$, those who have taken part in drama $(\mathrm{p}=0.408)$, toastmaster $(\mathrm{p}=0.876)$, singing $(\mathrm{p}=0.479)$, announcing $(\mathrm{p}=0.153)$, those who have followed 
courses related to public speaking $(\mathrm{p}=0.175)$ in the post PRPSA score.

Table 2 Associated factors for pre-assessment of PSA

\begin{tabular}{|c|c|c|c|c|}
\hline Characteristic & Component & Mean & SD & $\begin{array}{c}p \\
\text { value }\end{array}$ \\
\hline \multirow[t]{2}{*}{ Gender } & Male & 91.44 & 22.604 & \multirow[t]{2}{*}{0.042} \\
\hline & Female & 105.00 & 15.186 & \\
\hline \multirow[t]{2}{*}{ Drama } & No & 102.92 & 18.910 & \multirow[t]{2}{*}{0.931} \\
\hline & Yes & 102.48 & 18.095 & \\
\hline \multirow[t]{2}{*}{ Announcing } & No & 104.17 & 18.396 & \multirow[t]{2}{*}{0.070} \\
\hline & Yes & 88.60 & 10.644 & \\
\hline \multirow{4}{*}{$\begin{array}{l}\text { Highest } \\
\text { grade } \\
\text { obtained for } \\
\text { A/L }\end{array}$} & $\mathrm{A}$ & 100.81 & 19.413 & \multirow[t]{4}{*}{0.560} \\
\hline & B & 99.36 & 15.769 & \\
\hline & $\mathrm{C}$ & 107.50 & 19.090 & \\
\hline & $S$ & 112.00 & 9.899 & \\
\hline \multirow[t]{2}{*}{ Toastmaster } & No & 103.43 & 19.001 & \multirow[t]{2}{*}{0.524} \\
\hline & Yes & 99.11 & 14.962 & \\
\hline \multirow[t]{2}{*}{ Singing } & No & 102.29 & 18.288 & \multirow[t]{2}{*}{0.423} \\
\hline & Yes & 113.00 & 22.627 & \\
\hline \multirow[t]{2}{*}{ MUN } & No & 104.10 & 17.011 & \multirow[t]{2}{*}{0.004} \\
\hline & Yes & 67.00 & 18.385 & \\
\hline \multirow[t]{2}{*}{ Debating } & No & 107.92 & 15.546 & \multirow[t]{2}{*}{0.001} \\
\hline & Yes & 90.63 & 18.998 & \\
\hline \multirow{2}{*}{$\begin{array}{l}\text { Presented an } \\
\text { item before } \\
\text { an audience? }\end{array}$} & No & 116.14 & 19.196 & \multirow[t]{2}{*}{0.036} \\
\hline & Yes & 100.65 & 17.503 & \\
\hline \multirow{2}{*}{$\begin{array}{l}\text { Followed any } \\
\text { courses on } \\
\text { public } \\
\text { speaking }\end{array}$} & No & 105.49 & 16.844 & \multirow[t]{2}{*}{0.020} \\
\hline & Yes & 90.70 & 20.451 & \\
\hline
\end{tabular}

Further, the post-assessment has revealed that the post PRPSA score of those who have not done debating was statistically significantly higher than that of those who have done debating ( $\mathrm{U}=162, \mathrm{p}=0.009)$. It was also revealed that the post PRPSA score of those who have not engaged in MUN was statistically and significantly higher than that of those who have done MUN ( $\mathrm{U}=$ $3.00, p=0.024)$. Moreover, it was also highlighted that the post PRPSA score of those who have not presented an item in front of an audience was statistically and significantly higher than that of those who have not (U $=81.50, p=0.035)$. A Kruskal-Wallis H test showed no statistically significant difference in the post PRPSA score with the highest grades obtained for English at the GCE A/L examination $(\mathrm{p}=0.830)$.

\section{DISCUSSION}

The PSA is classified as one of the prevalent issues found among law undergraduates. One of the essential skills of a lawyer is good public speaking skills, and lawyers are supposed to maintain effective interactions with their clients. Further, they should be capable of delivering arguments convincingly and fruitfully in the courts. Hence, improving the public speaking skills of law undergraduates is one of the most valuable investments for their future. It has to be done at the initial stages of their university education. By the time they become graduates, they will be able to enter the world of professionalism with high levels of confidence (Brown, 2015). Therefore, it is essential to provide the university undergraduates with the necessary training to overcome the PSA before exposing themselves to the world of professionalism (Raja, 2017).

Moreover, due to the prevailing high levels in the PSA among university undergraduates, it is essential to take constructive measures to reduce the PSA (Heeren et al., 2013). However, it was noted that there were no interventional research studies conducted in Sri Lanka in reducing the PSA among the Law undergraduates, especially via the online platform. Hence, this study aimed to assess the effectiveness of an online teaching intervention in reducing the PSA among law undergraduates following a compulsory course module on public speaking. The online teaching intervention consisted of techniques such as gradual exposure, Communication Orientation Modification (COM), skills training, humour and simple breathing exercises.

As per the results of the current study, it was revealed that the 15 week online teaching intervention on managing the PSA has resulted in a statistically significant change in reducing the public speaking apprehension. Another similar experimental study has been carried out in Uva Wellassa University Sri-Lanka based on a group of third-year undergraduates following a compulsory module on public speaking. The study results have claimed that the undergraduates who were reported to have levels of PSA (64\%) in the initial stage have been able to reduce their PSA levels up to $5 \%$ at the end of the module. The mean values of the pre- and post-tests of the PRPSA in that particular study were $132.69( \pm 30.350)$ and $91.10( \pm 26.202)$, 
respectively (Herath, 2019). However, in the current study, mean values of the PRPSA in the pre and posttest were $102.70( \pm 18.321)$ and $82.50( \pm 18.672)$, respectively. It indicates that both pre- and post-test results are comparatively lower in the present study. The previous study was conducted based on students from different faculties. However, this study explicitly targeted law undergraduates who are expected to have speaking skills as a part of their profession, and that can be identified as one of the possible reasons for the low PRPSA mean values. Further, the exposure of the study sample into the defence setting and leadership programmes can also be identified as possible causes for the low levels of PSA. In addition, the previous exposure of the study participants in presenting an item in front of an audience and their engagement in extracurricular activities related to public speaking like Debating, Toastmaster and MUN must have influenced in resulting a low level of PSA.

Finding out the associated factors for the PSA was one of the specific objectives of the present study. As per the pre-assessment results, there was a significant mean difference in the PRPSA scores between the two genders; however, there was no significant difference between the two genders in the post-test. This study also found that the PRPSA score of the pre-test, the male participants had a statistically significantly lower score than the female participants. Cross-sectional research carried out amongst Brazilian students enrolled in higher education institutes found out that there had been no significant mean difference in PSA between the two genders (Marinho et al., 2019). Moreover, another study has revealed that there had been no significant mean difference in the PSA between the two genders (Johnson, 2012). The post-assessment data concluded that there had been no statistically significant difference between the two genders. It is possible to indicate that the reason for this change must be due to the effectiveness of the intervention. Both genders might have benefited equally from the intervention in reducing their PSA.

The results of both the pre- and post-tests have revealed that there had been a significant mean difference concerning the participants who have taken part in the extra-curricular activities like debating, MUN and those who had previous exposure to presenting an item in front of an audience. Further, a similar study has revealed that the previous exposure to extra-curricular activities impacted reducing the PSA (Johnson, 2012). In addition, a research study has revealed that the students who have done debating have proven to have better presentation skills in public speaking (Raja, 2017). Therefore, it is an indication that the prior experience of extra-curricular activities associated with public speaking can enhance the students' confidence levels, leading to low PSA levels.

\section{Conclusion and Recommendation}

The current study has revealed that the online teaching intervention conducted among the second-year Law undergraduates in managing the PSA has successfully reduced the PSA among the study participants. It has also been identified that prior experience in extracurricular activities associated with public speaking can reduce the PSA. Further experimental research is needed to assess associated factors related to PSA among law undergraduates. Reducing the PSA among law undergraduates can serve as a valuable investment for a successful future. It would lead to a positive alteration in their self-confidence, making them highly competent professionals.

\section{REFERENCES}

Anderson, P.L., Zimand, E., Hodges, L.F., Rothbaum, B.O., (2005). Cognitive behavioral therapy for publicspeaking anxiety using virtual reality for exposure. Depress Anxiety 22, pp.156-158. https://doi.org/10.1002/da.20090.

Arnold, J.K., n.d. Stress to Success: Public Speaking Anxiety and its Relationship to Perceived Leadership p.122.

Ayres, J., Hopf, T., Peterson, E., (2000). A test of communication-orientation motivation (COM) therapy. Communication Reports 13, pp. 35-44. https://doi.org/10.1080/08934210009367721

Bodie, G.D., (2010). A racing heart, rattling knees, and ruminative thoughts: Defining, explaining, and treating 
public speaking anxiety. Commun. Educ. 59, 70-105. doi:10.1080/03634520903443849.

Brown, H.K., (2015). Empowering Law Students to Overcome Extreme Public Speaking Anxiety: Why Just Be It Works and Just Do It Doesn't. Duquesne Law Rev. pp.53, 181.

Colbeck, J., (2011). The Impact of a Fundamentals of Speech Course on Public Speaking Anxiety. $J$. Undergrad. Res. 9.

Dwyer, K., Davidson, M., (2007). The Influence of Diaphragmatic Breathing to Reduce Situational Anxiety For Basic Course Students. Basic Communication Course Annual 7, pp. 104-137.

Ebrahimi, O.V., Pallesen, S., Kenter, R.M.F., Nordgreen, T., (2019). Psychological Interventions for the Fear of Public Speaking: A Meta-Analysis. Front. Psychol. 10 , 488. https://doi.org/10.3389/fpsyg.2019.00488.

Fasoro, A.A., Oluwadare, T., Ojo, T.F., Oni, I.O., (2019). Perceived stress and stressors among first-year undergraduate students at a private medical school in Nigeria. J. Taibah Univ. Med. Sci. 14, pp. 425-430. https://doi.org/10.1016/j.jtumed.2019.08.003.

Furmark, T., (2002). Social phobia: Overview of community surveys. Acta Psychiatr. Scand. 105, 8493. https://doi.org/10.1034/j.1600-0447.2002.1r103.x.

Galderisi, S., Heinz, A., Kastrup, M., Beezhold, J., Sartorius, N., (2015). Toward a new definition of mental health. World Psychiatry 14, 231-233. https://doi.org/10.1002/wps.20231.

Heeren, A., Ceschi, G., Valentiner, D., Dethier, V., Philippot, P., (2013). Assessing public speaking fear with the short form of the Personal Report of Confidence as a Speaker scale: Confirmatory factor analyses among a French-speaking community sample. Neuropsychiatr. Dis. Treat. 9, 609-18. https://doi.org/10.2147/NDT.S43097.

Herath, H., (2019). Effect of a Separate Course Module on Reducing Public Speaking Anxiety Among Undergraduates of Uva Wellassa University of Sri Lanka [WWW Document]. URL https://www.semanticscholar.org/paper/Effect-of-a-
Separate-Course-Module-on-Reducing-ofHerath/7a9ae33df82c42c71b1aba087b0ecfbffce7c2cc (accessed 8.14.21).

Ireland, C., (2018). Reducing Public Speaking Anxiety in Undergraduates: A Case Study of an Intervention with Accountancy Students. https://doi.org/10.13140/RG.2.2.16888.78082.

Johnson, K.H., (2012). The Effect of a High School Speech Course on Public Speaking Anxiety for Students in a College-Level Public Speaking Class, ProQuest LLC.

Jurewicz, I., (2015). Mental health in young adults and adolescents - supporting general physicians to provide holistic care. Clin. Med. 15, 151-154. https://doi.org/10.7861/clinmedicine.15-2-151.

Kerebih, H., Abera, M., Soboka, M., (2017). Pattern of Help Seeking Behavior for Common Mental Disorders among Urban Residents in Southwest Ethiopia. Qual. Prim. Care 25, pp. 208-216.

Keyes, K.M., Martins, S.S., Hatzenbuehler, M.L., Blanco, C., Bates, L.M., Hasin, D.S., (2012). Mental health service utilisation for psychiatric disorders among Latinos living in the United States: the role of ethnic subgroup, ethnic identity, and language/social preferences. Soc. Psychiatry Psychiatr. Epidemiol. 47, 383-394. https://doi.org/10.1007/s00127-010-0323-y.

Lamers, F., van Oppen, P., Comijs, H.C., Smit, J.H., Spinhoven, P., van Balkom, A.J.L.M., Nolen, W.A., Zitman, F.G., Beekman, A.T.F., Penninx, B.W.J.H., (2011). Comorbidity patterns of anxiety and depressive disorders in a large cohort study: the Netherlands Study of Depression and Anxiety (NESDA). J. Clin. Psychiatry 72, 341-348. https://doi.org/10.4088/JCP.10m06176blu.

Marinho, A.C.F., Medeiros, A.M. de, Lima, E. de P., Pantuza, J.J., Teixeira, L.C., (2019). Prevalence and factors associated with fear of public speaking. CoDAS 31. https://doi.org/10.1590/2317-1782/20192018266.

McLafferty, M., Lapsley, C.R., Ennis, E., Armour, C., Murphy, S., Bunting, B.P., Bjourson, A.J., Murray, E.K., O'Neill, S.M., (2017). Mental health, behavioural problems and treatment seeking among students 
commencing university in Northern Ireland. PloS One 12 , e0188785. https://doi.org/10.1371/journal.pone.0188785.

McLean, C.P., Asnaani, A., Litz, B.T., Hofmann, S.G., (2011). Gender Differences in Anxiety Disorders: Prevalence, Course of Illness, Comorbidity and Burden of Illness. J. Psychiatr. Res. 45, 1027-1035. https://doi.org/10.1016/j.jpsychires.2011.03.006.

Menéndez-Aller, Á., Postigo, Á., Montes-Álvarez, P., González-Primo, F.J., García-Cueto, E., (2020). Humor as a protective factor against anxiety and depression. Int. J. Clin. Health Psychol. 20, 38-45. https://doi.org/10.1016/j.ijchp.2019.12.002.

Mörtberg, E., Jansson-Fröjmark, M., Pettersson, A., Hennlid-Oredsson, T., (2018). Psychometric Properties of the Personal Report of Public Speaking Anxiety (PRPSA) in a Sample of University Students in Sweden. Int. J. Cogn. Ther. 11, 421-433. https://doi.org/10.1007/s41811-018-0022-0.

Motley, M.T., (1997). Overcoming Your Fear of Public Speaking: A Proven Method, 1st edition. ed. Pearson.

Mueser, K.T., Gottlieb, J.D., Xie, H., Lu, W., Yanos, P.T., Rosenberg, S.D., Silverstein, S.M., Duva, S.M., Minsky, S., Wolfe, R.S., McHugo, G.J., (2015). Evaluation of cognitive restructuring for post-traumatic stress disorder in people with severe mental illness. $\mathrm{Br}$ J Psychiatry 206, 501-508. https://doi.org/10.1192/bjp.bp.114.147926.

Mykletun, A., Bjerkeset, O., Dewey, M., Prince, M., Overland, S., Stewart, R., (2007). Anxiety, depression, and cause-specific mortality: the HUNT study. Psychosom. Med. 69, pp. 323-331. https://doi.org/10.1097/PSY.0b013e31803cb862.

Neer, M.A., Kirchner, W.F., (1991). Classroom Interventions for Reducing Public Speaking Anxiety 3, 23.

Orgilés, M., Morales, A., Delvecchio, E., Francisco, R., Mazzeschi, C., Pedro, M., Espada, J.P., (2021). Coping Behaviors and Psychological Disturbances in Youth Affected by the COVID-19 Health Crisis. Front.
Psychol.

12 ,

845. https://doi.org/10.3389/fpsyg.2021.565657.

Otorkpa, D., (2019). World Health Organization(WHO) Definition Of Health - Public Health. URL https://www.publichealth.com.ng/worldhealth-organizationwho-definition-of-health/ (accessed 8.14.21).

Pribyl, C.B., Keaten, J., Sakamoto, M., (2001). The effectiveness of a skills-based program in reducing public speaking anxiety. Jpn. Psychol. Res. 43, pp. 148-155. https://doi.org/10.1111/1468-5884.t01-100171.

Pull, C.B., (2012). Current status of knowledge on public-speaking anxiety. Curr. Opin. Psychiatry 25, 32-38.

https://doi.org/10.1097/YCO.0b013e32834e06dc

Raja, F.U., (2017). Anxiety Level in Students of Public Speaking: Causes and Remedies. J. Educ. Educ. Dev. 4, 94. https://doi.org/10.22555/joeed.v4i1.1001.

Sravani, A., Doshi, D., Kulkarni, S., Reddy, P., Reddy, S., (2018). Depression, anxiety, and stress among undergraduate dental students in Hyderabad City, Telangana, India: A cross-sectional study. J. Indian Assoc. Public Health Dent. 16, 26. https://doi.org/10.4103/jiaphd.jiaphd_10_17

WHO, (2020). Allen, M., Hunter, J., Donohue, W., 1989. Meta-analysis of self-report data on the effectiveness of public speaking anxiety treatment techniques. Commun. Educ. - COMMUN EDUC 38, 54-76._https://doi.org/10.1080/03634528909378740

Xu, Z., (2015). Laughing Matters: Humor Strategies in Public Speaking. Asian Social Science 12, 117. https://doi.org/10.5539/ass.v12n1p117.

Yasin, A.S., Dzulkifli, M., (2011). Differences in depression, anxiety and stress between low-and highachieving students. J. Sustain. Sci. Manag. 6, pp. 169178.

Yazdani, M., Rezaei, S., Pahlavanzadeh, S.,(2010). The effectiveness of stress management training program on depression, anxiety and stress of the nursing students. Iran. J. Nurs. Midwifery Res. 15, pp. 208-15. 